NBER WORKING PAPER SERIES

\title{
A MATHEMATICAL MODEL FOR ESTIMATING THE NUMBER OF HEALTH WORKERS REQUIRED FOR UNIVERSAL ANTIRETROVIRAL TREATMENT
}

\author{
Till Bärnighausen \\ David E. Bloom \\ Salal Humair \\ Working Paper 15517 \\ http://www.nber.org/papers/w15517
}
NATIONAL BUREAU OF ECONOMIC RESEARCH
1050 Massachusetts Avenue
Cambridge, MA 02138
November 2009

We thank Larry Rosenberg of the Harvard School of Public Health for his comments and assistance in the preparation of this paper. The views expressed herein are those of the author(s) and do not necessarily reflect the views of the National Bureau of Economic Research.

NBER working papers are circulated for discussion and comment purposes. They have not been peerreviewed or been subject to the review by the NBER Board of Directors that accompanies official NBER publications.

(C) 2009 by Till Bärnighausen, David E. Bloom, and Salal Humair. All rights reserved. Short sections of text, not to exceed two paragraphs, may be quoted without explicit permission provided that full credit, including $(\subset$ notice, is given to the source. 
A Mathematical Model for Estimating the Number of Health Workers Required for Universal Antiretroviral Treatment

Till Bärnighausen, David E. Bloom, and Salal Humair

NBER Working Paper No. 15517

November 2009

JEL No. I10,I11,I18,J20,J21

\section{ABSTRACT}

Despite recent international efforts to increase antiretroviral treatment (ART) coverage, it is estimated that more than 5 million people who need ART in developing countries do not receive such treatment. Shortages of human resources to treat HIV/AIDS (HRHA) are one of the main constraints to scaling up ART. We develop a discrete-time Markovian model to project the numbers of HRHA required to achieve universal ART coverage, taking into account the positive feedback from HRHA numbers to future HRHA need. Feedback occurs because ART is effective in prolonging the lives of HIV-positive people who need treatment, so that an increase in the number of people receiving treatment leads to an increase in the number of people needing it in future periods. We investigate the steady-state behavior of our model and apply it to different regions in the developing world. We find that taking into account the feedback from the current supply of HRHA to the future HRHA need substantially increases the projected numbers of HRHA required to achieve universal ART coverage. We discuss the policy implications of our model.

Till Bärnighausen

Harvard School of Public Health

Department of Global Health and Population

665 Huntington Ave.

Boston, MA 02115

and Africa Centre for Health and Population

Studies, University of KwaZulu-Natal

tbaernig@hsph.harvard.edu

David E. Bloom

Harvard School of Public Health

Department of Global Health and Population

665 Huntington Ave.

Boston, MA 02115

and NBER

dbloom@hsph.harvard.edu
Salal Humair

Harvard School of Public Health

Department of Global Health and Population

665 Huntington Ave.

Boston, MA 02115

and School of Science and Engineering

Lahore University of Management Sciences

Lahore, Pakistan

shumair@hsph.harvard.edu 


\section{Introduction}

Despite recent international initiatives to scale up antiretroviral treatment (ART) (Clinton Foundation 2007; Global Fund to Fight AIDS, Tuberculosis and Malaria 2007; Médecins Sans Frontières 2007a; President's Emergency Plan For AIDS Relief (PEPFAR) 2007), more than 5 million people in developing countries who needed ART in December 2008 did not receive it (World Health Organization (WHO), Joint United Nations Programme on HIVIAIDS (UNAIDS), United Nations Children's Fund (UNICEF) 2009). The result of such shortfalls is a large number of potentially avoidable deaths (Hogg et al. 1999; Bärnighausen 2007). In June 2006, the General Assembly of the United Nations committed itself to the goal of achieving universal ART coverage by 2010 (United Nations 2007), but in December 2008 worldwide ART coverage was reported to stand at only $42 \%$, suggesting that this goal will not be reached (WHO, UNAIDS and UNICEF 2009).

In many developing countries, the limiting factor in increasing ART coverage is not drugs, laboratory equipment, or facilities, but human resources to treat HIVIAIDS (HRHA) (Clark 2006; Hosseinipour et al. 2002; Institute of Medicine 2007; Kober, and Van Damme 2004; Marchal, De Brouwere, and Kegels 2005; Marchal, Kegels, and De Brouwere 2004; Médecins Sans Frontières 2007b; Ooms, Van Damme, and Temmerman 2007; Van Damme, Kober, and Laga 2006; WHO 2006a). Realistic estimates of the number of health workers required to achieve and maintain universal ART coverage in future years are necessary to the development of appropriate strategies for health worker education, training, and retention (Bärnighausen 2007).

Estimating the number of additional HRHA currently needed to achieve universal ART coverage in developing countries is relatively easy, using, for instance, recent empirical estimates of the number of health workers needed to provide ART to 1,000 patients in developing countries (Hirschhorn et al. 2006) and estimates of current unmet need for ART (WHO 2007). However, such static estimation of HRHA need is of limited value for a number of reasons. First, the number of HRHA needed to achieve universal ART 
coverage in the future is not independent of the current numbers of HRHA. The more $\mathrm{HRHA}$ that are available, the larger the number of people who currently receive ART will be, and because ART is a lifelong treatment effective in prolonging the lives of people needing the treatment (Braitstein et al. 2006; Merson, Dayton, and O'Reilly 2000; Herbst et al. 2009), the larger the number of people who require ART in the future will become. This constitutes a positive feedback from HRHA numbers to future HRHA need (Bärnighausen, Bloom and Humair 2007).

Second, while most of the other inputs needed to provide ART, such as antiretroviral drugs and medicines to prevent and treat opportunistic infections, laboratory equipment to measure CD4 counts, and health care facilities, can be scaled up relatively quickly given sufficient funds, HRHA cannot be increased quickly, because of long education and training times (Bossert et al. 2007). Any estimation of HRHA need must thus span a period of many years.

Third, HRHA themselves are at risk of contracting HIV and becoming patients in need of ART, especially in countries with generalized HIV epidemics (Connelly et al. 2007; Ncayiyana 2004). In many developing countries, large numbers of health workers in need of ART are not receiving it (Chen and Hanvoravongchai 2005; Shisana 2007; Tawfik and Kinoti 2003). We would expect that the probability of a health worker receiving ART increases with increasing numbers of HRHA per capita. ART will increase the life expectancy of HIV-positive HRHA, and thus decrease the need for HRHA over time. This is a negative feedback from HRHA numbers to future HRHA need.

In this paper, we develop a mathematical model to estimate the numbers of HRHA required to achieve universal ART coverage, taking into account feedback from HRHA numbers to future HRHA need. In section II, we describe the model conceptually. In section III, we develop the model formally. In section IV, we analyze the steady state properties of the model under varying assumptions about HRHA inflow from the health worker education system and outflow because of emigration, retirement, or death. In 
section $\mathrm{V}$, we apply the model to different regions in the developing world. We conclude with a discussion of our findings in section VI.

\section{Conceptual description of the model}

Our model is a simple, discrete-time, Markovian deterministic system with two main population pools (Law and Kelton 2000): HRHA and people needing ART. ${ }^{1}$ In order to investigate whether changes in HRHA HIV incidence or HRHA ART coverage appreciably change the long-term need to add HRHA to the pool of existing health workers, we divide HRHA into four subpopulations: HIV-negative HRHA, HIV-positive HRHA who do not (yet) need ART, HIV-positive HRHA who need ART but are not receiving it, and HIV-positive HRHA needing and receiving ART. Time increments are yearly.

The patient population needing ART, starting from a given initial size at time $t=0$, evolves as follows. At the beginning of each period $t$, new infections occur at a given annual rate. The newly HIV-positive people then enter a fixed latency period of 10 years during which they are exposed to general population mortality, but do not yet need ART. The HIV-positive people who survive the latency period enter the population needing treatment at the beginning of each period. The previous period's treated and untreated population sizes are then reduced using their respective annual mortality rates.

Given the current number of HRHA, the number of patients treated is computed assuming a fixed HRHA-to-patient ratio of 1 team to 1,000 patients. A recent review of staffing patterns in ART programs in developing countries found that one to two doctors, up to three pharmacy staff, and two to seven nurses were used to provide ART to 1,000

\footnotetext{
${ }^{1}$ In this paper, we use the term "people needing ART" to denote the sum of people who need ART and receive it and people who need ART and do not receive it. Currently, WHO recommends that the following categories of patients should receive ART: first, patients with advanced clinical HIV disease (WHO HIV disease stage IV, regardless of CD4 cell count or stage III with CD4 cell count below 350 cells per microliter) and, second, patients with laboratory evidence of severe immunosuppression (CD4 cell count below 200 per microliter, irrespective of disease stage) (WHO 2006b).
} 
patients (Hirschhorn et al. 2006). In addition to these highly skilled health workers, ART programs commonly use lower-skilled cadres of health worker, such as treatment counselors and adherence supporters (Hirschhorn et al. 2006). The ratio used in this model employs the lower bound of the number of doctors needed to provide ART to 1,000 patients: by scaling our estimates of HRHA need by a constant factor, we can easily translate them into the need for nurses, pharmacy staff, or treatment counselors. In our model, one HRHA represents a team of health workers sufficient to provide ART to 1,000 patients. The precise makeup of the team is irrelevant to our model. The only assumptions necessary for our results to hold are, first, that the provision of ART by health workers is as effective in reducing mortality as is the provision of ART during the first phase of ART scale-up in low-income countries (Braitstein et al. 2006), and second, that health workers are internationally mobile.

The evolution of HRHA in the model is similar, in principle, to the evolution of the population needing ART, but more detailed. The size of the HIV-negative HRHA pool decreases in each period because of mortality and emigration. The remaining number of HIV-negative HRHA is further diminished because of new HIV infections. At the same time, new HRHA are added to the subpopulation of HIV-negative HRHA at a given annual rate, yielding the HIV-negative HRHA population at the start of the next period. During the latency period from HIV infection to ART need, the size of the HIV-positive HRHA pool is decreased because of mortality and emigration. HRHA who neither die nor emigrate during the 10 years from infection to need for treatment are added to the subpopulation of HIV-positive HRHA needing ART.

The HRHA who need treatment at the beginning of a period are split into two subpopulations: those who received treatment during the previous period and those who did not. Both subpopulations are reduced by their respective mortality and emigration rates. The number of HRHA needing treatment in the current period is computed as the sum of the HRHA needing treatment who have remained in the subpopulation from the previous period and the HIV-positive HRHA who have newly become in need of ART. 


\section{Mathematical formulation of the model}

We now present the mathematical formulation of our model.

Notation

$t \quad=$ time period, $t=0, \ldots, \infty$.

$L \quad=$ latency period from start of infection to time of needing ART (for both HRHA and patients in the general population).

$\phi \quad=$ number of HIVIAIDS patients treatable by one HRHA.

$H_{t}^{H}=$ number of healthy $\mathrm{HRHA}$ at the beginning of period $t$.

$H_{t}^{I k}=$ number of HIV-infected HRHA who do not yet need ART at the beginning of period $t$, who were infected $k$ periods ago, $k=0, \ldots, L-1$.

$H_{t}^{N}=$ number of HRHA needing ART at the beginning of period $t$.

$H_{t}^{T}=$ number of HRHA needing and receiving ART at the beginning of period $t$.

$H_{t}^{U}=$ number of HRHA needing but not receiving ART at the beginning of period $t$.

$H_{t}=$ total number of HRHA at the beginning of period $t$.

$P_{t}^{T} \quad=$ population receiving ART at the beginning of period $t$.

$P_{t}^{U}=$ population needing but not receiving ART at the beginning of period $t$.

$P_{t} \quad=$ total population needing ART at the beginning of period $t$.

The term 'rate', below, always means a fraction of the existing population and is always per period. It can be viewed as the annual probability of an individual in the population experiencing an event (for instance, the annual probability of death, HIV infection, or emigration).

$m^{H}, m^{I}, m^{T}, m^{U}=$ mortality rates for healthy, infected, treated, and untreated HRHA. 
$e^{H}, e^{I}, e^{T}, e^{U}=$ emigration rates for healthy, infected, treated, and untreated HRHA.

$m^{T P}, m^{U P}=$ mortality rates for people needing and receiving ART, and for people needing but not receiving ART.

$m^{G}=$ mortality rate for the general population.

$i^{H} \quad=$ HRHA HIV incidence rate.

$a^{H}=$ number of new HRHA per period.

$a^{P} \quad=$ number of people newly infected with HIV per period.

$c_{t}^{H} \quad=$ HRHA ART coverage in period $t$.

$c_{t} \quad=$ population ART coverage in period $t$.

We assume regularity conditions on the parameters of the form $m^{H}+e^{H} \leq 1$, $m^{I}+e^{I} \leq 1, m^{T}+e^{T} \leq 1, m^{U}+e^{U} \leq 1$.

Formulation

The following formulation assumes that all quantities are continuous. Initial values at $t=0$ for all quantities indexed by $t$ are given. Then for $t=1,2, \ldots, \infty$, the HRHA population evolves as follows: 


$$
\begin{aligned}
& H_{t}^{H}=a^{H}+\left(1-i^{H}\right)\left(1-m^{H}-e^{H}\right) H_{t-1}^{H}, \\
& H_{t}^{I 0}=i^{H}\left(1-m^{H}-e^{H}\right) H_{t-1}^{H}, \\
& H_{t}^{I 1}=\left(1-m^{I}-e^{I}\right) H_{t-1}^{I 0}, \\
& \vdots \\
& H_{t}^{L L-1}=\left(1-m^{I}-e^{I}\right) H_{t-1}^{L L-2}, \\
& H_{t}^{N}=\left(1-m^{I}-e^{I}\right) H_{t-1}^{L-1}+\left(1-m^{T}-e^{T}\right) H_{t-1}^{T}+\left(1-m^{U}-e^{U}\right) H_{t-1}^{U}, \\
& H_{t}^{T}=c_{t}^{H} H_{t}^{N}, \\
& H_{t}^{U}=\left(1-c_{t}^{H}\right) H_{t}^{N}, \\
& H_{t}=H_{t}^{H}+H_{t}^{I 0}+\cdots+H_{t}^{L L-1}+H_{t}^{N} .
\end{aligned}
$$

If HRHA coverage is exogenous and time independent, $c_{t}^{H}$ is some constant $c^{H}$. Therefore, the foregoing equations completely describe the evolution of HRHA over time. If HRHA ART coverage is endogenous but the same as population ART coverage, then the evolution of HRHA is completely specified by using $c_{t}^{H}=\min \left(\phi H_{t} / P_{t}, 1.0\right)$, where $P_{t}$ is obtained from the following population evolution equations for $t=1,2, \ldots, \infty$ :

$$
\begin{aligned}
& P_{t}=a^{P}\left(1-m^{G}\right)^{L}+\left(1-m^{T P}\right) P_{t-1}^{T}+\left(1-m^{U P}\right) P_{t-1}^{U}, \\
& P_{t}^{T}=\min \left(\phi H_{t}, P_{t}\right) \\
& P_{t}^{U}=P_{t}-\min \left(\phi H_{t}, P_{t}\right) .
\end{aligned}
$$

\section{Analysis of steady state behavior}

HRHA needed for universal population ART coverage in the steady state 
At universal coverage $\phi H_{\infty}=P_{\infty}$ (where $\infty$ denotes steady state). In steady state, patient inflow must equal patient outflow, that is, $a^{P}\left(1-m^{G}\right)^{L}=P_{\infty} m^{T P}$, which gives the following equation for universal coverage:

$$
H_{\infty}=\frac{a^{P}\left(1-m^{G}\right)^{L}}{\phi m^{T P}} .
$$

The expression above allows us to compare HRHA requirements for universal population ART coverage in a model with feedback (caused by a lower mortality rate among those receiving versus those not receiving ART) with requirements in a model without feedback. Given the mortality rates from Table $1, m^{T P}=0.05$, and $m^{U P}=0.23$, the model without feedback would use $m^{U P}=0.23$ in the above expression in place of $m^{T P}$. The model with feedback therefore requires 4.6 times more HRHA for universal coverage in steady state than the model without feedback.

HRHA requirement as a function of a pre-specified steady-state population ART coverage $0 \leq c \leq 1$

In steady state, we must have $a^{P}\left(1-m^{G}\right)^{L}=P_{\infty}\left(c m^{T P}+(1-c) m^{U P}\right)$. With $c=\phi H_{\infty} / P_{\infty}$, this gives

$$
H_{\infty}=\frac{c a^{P}\left(1-m^{G}\right)^{L}}{\phi\left(c m^{T P}+(1-c) m^{U P}\right)} .
$$

Figure 4 shows how the annual inflow of HRHA required to reach steady state for a model with feedback increases nonlinearly with desired population coverage, compared with a linear increase for a model without feedback. The magnitude of the difference indicates the impact of feedback. The required number of HRHA for the model with feedback is 1.6 times that for a model without feedback at 50 percent coverage, 2.4 times at 75 percent coverage, 3.4 times at 90 percent coverage, and 4.6 times at 100 percent coverage. 


\section{$<$ Figure $4>$}

Computing steady-state population ART coverage for given model parameters

To compute the steady-state coverage for a given a set of model parameters, we can obtain the steady-state versions of HRHA subpopulations in the exogenous HRHA coverage case as follows:

$$
\begin{aligned}
& H_{\infty}^{H}=\frac{a^{H}}{m^{H}+e^{H}+i^{H}\left(1-m^{H}-e^{H}\right)}, \\
& H_{\infty}^{I 0}=i^{H}\left(1-m^{H}-e^{H}\right) H_{\infty}^{H}, \\
& H_{\infty}^{I 1}=i^{H}\left(1-m^{H}-e^{H}\right)\left(1-m^{I}-e^{I}\right) H_{\infty}^{H}, \\
& \vdots \\
& H_{\infty}^{L-1}=i^{H}\left(1-m^{H}-e^{H}\right)\left(1-m^{I}-e^{I}\right)^{L-1} H_{\infty}^{H} .
\end{aligned}
$$

For exogenous HRHA coverage, $H_{\infty}^{T}=c^{H} H_{\infty}^{N}, H_{\infty}^{U}=\left(1-c^{H}\right) H_{\infty}^{N}$, which gives

$$
\begin{aligned}
& H_{\infty}^{N}=\frac{i^{H}\left(1-m^{H}-e^{H}\right)\left(1-m^{I}-e^{I}\right)^{L} H_{\infty}^{H}}{1-c^{H}\left(1-m^{T}-e^{T}\right)-\left(1-c^{H}\right)\left(1-m^{U}-e^{U}\right)}, \\
& H_{\infty}=H_{\infty}^{H}\left[1+i^{H}\left(1-m^{H}-e^{H}\right)\left(\begin{array}{c}
1+\left(1-m^{I}-e^{I}\right)+\cdots+\left(1-m^{I}-e^{I}\right)^{L-1}+ \\
\left.\frac{\left(1-m^{I}-e^{I}\right)^{L}}{1-c^{H}\left(1-m^{T}-e^{T}\right)-\left(1-c^{H}\right)\left(1-m^{U}-e^{U}\right)}\right)
\end{array}\right] .\right.
\end{aligned}
$$

The foregoing formulae readily allow the steady-state HRHA pool size to be computed. The sensitivity of the HRHA pool size to changes in various parameters - such as HRHA coverage, emigration, and HIV incidence rates - can then be plotted over their 
full range. Figures 5-7 show plots of steady-state HRHA pool size for SSA by HRHA ART coverage, HRHA emigration rate, and HRHA ART coverage, respectively. Figure 8 shows the plot of HRHA pool size for SSA when all three parameters (HRH ART coverage, HRHA emigration rate and HRHA ART) coverage are simultaneously increased from $0 \%$ to $100 \%$.

$<$ Figures 5-8 >

Figure 5 shows that HRHA emigration rate for SSA has the most pronounced effect on decreasing the steady-state HRHA pool size in the $0-40 \%$ emigration range. If fewer HRHA are available, fewer emigrate. Therefore at lower HRHA pool sizes the effects of emigration in reducing the HRHA pool size become smaller. However, emigration rates affect healthy and infected HRHA equally, so the proportion of healthy to infected HRHA remains unaltered by emigration rates.

Figure 6 shows that the steady-state HRHA pool size for SSA is relatively insensitive to changes in the HRHA HIV incidence rate, but that the number of infected HRHA is quite sensitive to such changes. This peculiarity is due to the high emigration rate for SSA (0.09), a rate that is higher than the mortality rate of healthy HRHA (0.06). Most infected HRHA therefore emigrate or die within their 10-year latency period, at a level comparable to their combined emigration and mortality rate if they had not been infected. This makes the total HRHA pool size insensitive to the HRHA HIV incidence rate, even though at any given time high HRHA HIV incidence means more HRHA are infected, as shown in Figure 6.

Figure 7 shows the above phenomenon from another view. Because few infected HRHA survive emigration or mortality through the 10-year latency period, HRHA ART coverage does not have an appreciable effect on the total HRHA pool size. The number of healthy HRHA is of course independent of the HRHA ART coverage and is shown in Figure 7 only for comparison. 
In the exogenous HRHA coverage case, $H_{\infty}$ evolves independently of the patient population. The steady-state patient population can then be computed from the expression $a^{P}\left(1-m^{G}\right)^{L}=\min \left(\phi H_{\infty}, P_{\infty}\right) m^{T P}+\left(P_{\infty}-\min \left(\phi H_{\infty}, P_{\infty}\right)\right) m^{U P}$. This gives

$$
\begin{cases}P_{\infty}=\frac{a^{P}\left(1-m^{G}\right)^{L}+\phi H_{\infty}\left(m^{U P}-m^{T P}\right)}{m^{U P}}, & \text { if } H_{\infty} \leq \frac{a^{P}\left(1-m^{G}\right)^{L}}{\phi m^{T P}}, \\ P_{\infty}=\frac{a^{P}\left(1-m^{G}\right)^{L}}{m^{T P}}, \quad o / w .\end{cases}
$$

In summary, the steady-state HRHA pool size, and thus population ART coverage, is very sensitive to changes in the HRHA emigration rate and is insensitive to changes in HRHA HIV incidence and HRHA ART coverage (Figures 5-8). Figure 5 shows that the sensitivity of the steady-state $\mathrm{HRH}$ pool size to changes in HRHA emigration rates increases with decreasing emigration rates. Figures 6 and 7 show that the steady-state $\mathrm{HRH}$ pool size is insensitive to changes in HRHA HIV incidence and HRHA ART coverage over the entire range of the two parameters.

\section{Application of the model}

In this section, we apply our model to three regions in the developing world. We divided all developing countries into two separate base cases, sub-Saharan Africa (SSA) and non-sub Saharan African (NSSA). We chose these base cases because the HIV epidemic (WHO 2007), health worker emigration (Docquier and Bhargava 2007b), and mortality (World Bank 2007) are very different in these two sets of countries, and we would thus expect our model to yield substantially different results in the two regions. We added a third base case, the country of South Africa (SA). As SA has considerably higher HIV prevalence, HIV incidence, and HRHA emigration rates than both the SSA and the NSSA averages, the base case SA enables us to investigate in how far model predictions differ for countries with such characteristics. In addition, SA represents an 
important case, because it is currently the country with the worldwide largest absolute number of people receiving ART (WHO, UNAIDS and UNICEF 2009).

\section{Parameter estimates}

Table 1 presents estimates for model parameters for three regional base cases, as derived from published studies. Rate estimates from literature for parameters such as HIV incidence, mortality or emigration are converted into annual probabilities, because we model time as a series of discrete one-year-long units.

\section{$<$ Table $1>$}

The initial estimates of the number of people receiving ART and the number of people needing but not receiving ART in the three base cases are from a joint publication by WHO, UNAIDS, and UNICEF (WHO, UNAIDS and UNICEF 2007). Estimates of mortality among people receiving ART are based on a review of mortality in 18 ART programs in low-income countries (Braitstein et al. 2006). Estimates of mortality among people needing ART but not receiving it are taken from a study undertaken in South Africa (Badri, Lawn, and Wood 2006).

During the early phases of the HIV epidemic in developing countries, people with high educational attainment, such as health workers, were at higher risk of HIV infection than the general population (Hargreaves and Glynn 2002). However, recent studies of HIV infection among health workers have found HIV prevalence in health workers to be similar to the prevalence in the general population (Connelly et al. 2007; Shisana et al. 2004). Therefore for the initial split into HIV-negative and HIV-positive HRHA subpopulations, we assume that HIV prevalence and HIV incidence among health workers equals the prevalence and incidence in the general adult population in the three regional base cases. We calculate the annual probability of HIV infection for people in SSA and NSSA countries using estimated numbers (by world region) of people who were newly infected with HIV during 2007 and estimated numbers of people who need 
to be excluded from the population at risk of HIV incidence in 2007 because they have already contracted HIV (UNAIDS and WHO 2007). We derive our estimate of the annual probability of HIV acquisition for SA from the 2005 South African National HIV Prevalence, HIV Incidence, Behaviour, and Communication Survey (Rehle et al. 2007; Shisana et al. 2005).

We assume that $15 \%$ of HIV-positive HRHA are initially in need of ART. This number falls within the range of the proportion of HIV-positive people needing treatment as found in studies across Africa (1\% - 34\%) (Williams et al. 2006) when ART need is defined according to current WHO guidelines (WHO 2006b).

We use a recently published dataset, Medical Brain Drain: Physicians' Emigration Rates 1991-2004, to derive annual probabilities of HRHA emigration (Docquier and Bhargava 2007a). Docquier and Bhargava use annual reports on physician immigration from 16 countries belonging to the Organisation for Economic Co-operation and Development (OECD) and data on physician numbers from the World Development Indicators to derive annual estimates of doctors' emigration rates for 192 countries (Docquier and Bhargava 2007b). We take estimates of the number of doctors from the same dataset (for each country-year) as the weighting factor to calculate a weighted average annual emigration probability for SSA and NSSA. We use the most recent estimate of the probability of annual doctor emigration available for the SA base case (i.e. for the year 2004) (Docquier and Bhargava 2007a).

In addition to emigration, we assume that health workers leave the HRHA pool because they retire or die. We derive a combined annual probability of either of the two events from an estimate of the work lifetime of HIV-negative HRHA. In NSSA, we calculate the work lifetime as the time in years from an assumed average health worker age of 30 years to a retirement age of 60 years. In countries in which life expectancies are lower than 60 years, we use the difference between life expectancy and 30 years as estimates of the work lifetime in these two cases. As an estimate of the life expectancy in SSA, we use the weighted average of life expectancies across the countries in the 
region, where the weighting factors are the country population sizes from the World Development Indicators (World Bank 2007). Estimates of new health workers added annually to the HRHA pool are inferred by assuming the current HRHA populations in the three regions are in steady state given the rate at which HRHA currently leave the pool.

Descriptive results

If the HRHA inflow and emigration rates remain at base-case levels, in 10 years ART coverage will have dropped in all three regional base-case scenarios, most substantially in SA, less in SSA, and least in NSSA (Figure 1). Table 2 shows results for the three regional base-case scenarios and for univariate sensitivity analyses when individual model parameters are varied. Table 3 shows the number of HRHA that need to be added to the existing HRHA population each year to achieve universal ART coverage in 10 years.

$<$ Figure 1, Table 2, Table 3 >

Result 1: In all three base cases, the positive feedback from HRHA numbers to HRHA need (due to the effect of ART on mortality) is significant. At higher levels of ART coverage the feedback effect becomes larger; at near-universal coverage it is the main determinant of HRHA need.

Under base-case assumptions, ART coverage is lower for the model with feedback than for the model without feedback (by 3-7 percentage points). For the model with feedback, outputs are listed in Tables 2 and 3. Without feedback, 22-35\% ART coverage is obtained by year 10 (30\% in SSA; $35 \%$ in NSSA; $22 \%$ in SA) as well as in steady state. With feedback, as shown in Table 2 and Figure 1, coverage in year 10 drops to 19-28\% (25\% in SSA; $28 \%$ in NSSA; $19 \%$ in SA) and remains approximately at that level in steady state. At or near universal coverage, the feedback effect is the main determinant of HRHA need. Without feedback, the HRHA inflow rate required to achieve universal 
coverage in year 10 is $788 \mathrm{HRHA}$ per year in SSA (0.6 times the size of the current HRHA population in the region), $199 \mathrm{HRHA}$ per year in NSSA (0.3 times the size of the current HRHA population), and 494 HRHA per year in SA (1.5 times the size of the current HRHA population). With feedback, as shown in Table 3, this rate is 2.5 times higher in SSA $(1,931 \mathrm{HRHA}$ per year or 1.4 times the size of the current HRHA population in the region), 2.7 times higher in NSSA (532 HRHA per year or 0.8 times the size of the current HRHA population), and 2.2 times higher in SA (1085 HRHA per year or 2.2 times the size of the current HRHA population). Feedback also significantly affects the sustainability of universal ART coverage beyond year 10. For instance, without feedback, universal coverage with 1,287 HRHA per year is sustainable beyond year 10 for SSA (119\% coverage in steady state). Similarly, universal coverage is easily sustainable with rates of $199 \mathrm{HRHA}$ per year for NSSA (190\% coverage in steady state) and 494 HRHA per year for SA in steady state (99\% coverage in steady state). With feedback however, as shown in Figure 2, universal ART coverage beyond year 10 is not sustainable for SSA with an inflow of 1,931 HRHA per year. Indeed, steady-state universal coverage would require an inflow of 3,028 HRHA per year for SSA (469 for NSSA and 2,294 for SA).

$<$ Figure $2>$

Result 2: HRHA ART coverage does not appreciably affect total population ART coverage in steady state. The reasons for this vary for the different regions (Table 2 and Figure 3).

$<$ Figure $3>$

In NSSA, the total HRHA population (675) is small enough and the incidence of HIV among HRHA is low enough ( $0.024 \%$ per year) that almost no infected HRHA enter the pool of HIV-positive HRHA needing treatment every year. Therefore the need for ART among HRHA is essentially zero. In SA, the incidence of HIV among HRHA is higher (2.4\% per year) but HRHA emigration is so high (28\% per year, compared with $9 \%$ per 
year for SSA and $2 \%$ per year for NSSA) that only a negligible number of HRHA enter the pool of HIV-positive HRHA needing treatment every year. In SSA, HRH HIV incidence is considerable ( $0.421 \%$ per year), but the number of HRHA needing treatment in steady state is small (4 out of a total of 1,334), so that population ART coverage in SSA is insensitive to changes in HRHA ART coverage.

Result 3: HRHA inflow and emigration have the most significant effects on population ART coverage (Table 2 and Figure 3).

A 25\% increase in HRHA inflow increases ART coverage among the overall population by $9-21 \%$ ( $16 \%$ in SSA; $9 \%$ in NSSA; $21 \%$ in SA). A 25\% decrease in HRHA emigration increases ART coverage by $11 \%$ in SSA, by $22 \%$ in SA, and by $3 \%$ in NSSA. Setting emigration to zero has a drastic effect on population ART coverage, increasing coverage in year 10 by $54 \%$ in SSA, by $157 \%$ in SA, and by $14 \%$ in NSSA.

Result 4: Sustainable universal population ART coverage in SSA and SA can be achieved beyond year 10 with much lower increases in HRHA inflow if HRHA emigration is reduced. The alternative to reducing emigration is a several-fold increase in HRHA inflow (Table 3 and Figure 2).

In order to achieve universal population ART coverage in SSA in year 10, we can increase the HRHA inflow to 1,931 HRHA per year. However, at this level of HRHA inflow and the base-case emigration level, universal ART coverage is not sustainable and drops to $89 \%$ in steady state (Figure 2). If, by contrast, HRHA emigration is set to zero, we need a substantially smaller HRHA inflow rate (1,262 HRHA per year) to both achieve universal ART coverage in year 10 and sustain it in steady state. In SA, universal coverage is obtained in year 10 with an HRHA inflow rate of 1,085 per year, but - because of high base-case HRHA emigration (28\% per year) - ART coverage falls to $80 \%$ in steady state. In contrast, if emigration from SA is reduced to zero, universal coverage can be maintained by an inflow rate of 399 per year. In NSSA, the HRHA inflow rate required to achieve universal coverage by year 10 (532 HRHA per year) will 
be sufficient to sustain universal coverage in steady state without decreasing the level of HRHA emigration below its base-case value (because at $2 \%$ per year base-case emigration is already low).

\section{Discussion}

The descriptive results taken together with the analytical results show clearly the substantial effect of feedback on estimates of HRHA needed for universal ART coverage. But the impact of the model must be examined through its policy implications, which we discuss below.

Policy implication 1: Strategies to achieve universal ART coverage in developing countries are bound to fail if they do not take into account that higher current HRHA numbers will lead to higher future HRHA need.

One motivation for our model was to understand if ignoring the feedback from HRHA numbers on HRHA need in ART programs is inadvisable. In this regard, we find that even at relatively low initial ART coverage, ignoring feedback may result in substantial overestimation of the population ART coverage that can be achieved in the long run. Moreover, as ART coverage increases, the feedback effect becomes increasingly important. For instance, without feedback, an annual inflow of at least 788 HRHA would be required to achieve universal ART coverage in SSA within 10 years. With feedback, that number would rise to an annual inflow of 1,931 HRHA. If no feedback occurred, the HRHA inflow needed to achieve universal ART coverage within 10 years would be sufficient to maintain near-universal coverage beyond year 10 , but with feedback universal coverage could not be sustained beyond year 10 at that inflow rate.

In fact, as ART programs in developing countries continue to scale up treatment in the coming years, they will increasingly fall victim to their own success, constantly needing to increase the number of HRHA simply to maintain ART coverage levels. To make this point concrete, consider the example of SSA with base-case values. Even if we 
assume that HRHA do not suffer from increased mortality due to HIV, if we started with 2,400 HRHA for $50 \%$ coverage, to maintain this coverage level, the HRHA population would need to increase to 2,573 next year, 2,722 the year after, and in subsequent years to $2,850,2,960,3,054,3,135$, and so on. Steady state will eventually be reached with an HRHA population of 3,632 to 3,635 but only after about 40 years, until which time HRHA numbers will have to increase just to maintain $50 \%$ coverage.

Policy implication 2: Even to maintain current levels of ART coverage in developing countries, health policies must be put into place to either increase the number of HRHA, reduce HIV incidence, or change the organization of ART delivery.

The feedback effect from the current level of HRHA to future HRHA need is moderately large at current levels of population ART coverage. We find that under base-case assumptions current levels of coverage will not be maintained in SSA and SA because of the continued high inflow of people needing ART. If inflows into the pool of HRHA and outflows caused by emigration or death remain at their current levels, ART coverage will decline to some extent in both SSA and SA.

This conclusion from our model rests on the assumption that the estimated inflow of people into the pool of those needing treatment is valid and that HIV incidence in the three base-case regions has been approximately constant over the last 10 years. The rate of inflow of people needing ART is a function of HIV incidence and mortality during the latency period between HIV infection and treatment, two parameters that are uncertain. For instance, UNAIDS and WHO provide a range of 1.4 million to 2.4 million people around their estimate of 1.7 million people newly infected with HIV in SSA during 2007 as the "boundaries within which the actual numbers lie, based on the best available information" (UNAIDS and WHO 2007). Despite this uncertainty in the precise parameter values, our conclusion that current levels of ART coverage will not be maintained under base-case assumptions is robust to substantial changes in the basecase patient inflow rate. 
Our model does not take into account other effects of increased HRHA that may affect future need for HRHA, such as reductions in the probability of HIV transmission per risky sex act (because ART reduces viral load) (Quinn et al. 2000) and changes in risk behavior because of the availability of ART (Kennedy et al. 2007). Future models need to investigate whether such effects could alter the main results of our study.

Our model further assumes that the number of HRHA needed to treat 1,000 patients is constant over time. Changes in the mix of patients, the need for treatment, treatment technology, or experience may make an adjustment to the HRHA-to-patient ratio necessary. One plausible expectation is that more health workers will be needed to treat a fixed number of patients as ART programs mature. Patients in initial treatment cohorts may, on average, require less HRHA time because they are healthier, better educated, or have more effective social support than patients who access ART in later stages of ART roll-out. In addition, as the average time on ART increases, adherence failure (Mannheimer et al. 2006), ART failure due to viral resistance, and adverse events associated with ART (Orrell et al. 2007) will become more common, thereby increasing the amount of time that HRHA need to spend per patient.

On the other hand, it is also possible that technological advances, such as combination pills or increasing experience in providing ART among HRHA, could reduce the HRHAto-patient ratio over time. Furthermore, knowledge about how to take antiretroviral medicines and how to deal with the side effects of ART may spread through the population as more patients gain treatment experience, in turn reducing time-consuming interactions between patients and HRHA.

Finally, decreases in the HRHA-to-patient ratio could be achieved through changes in the organization of ART delivery. For instance, according to the current National Antiretroviral Treatment Guidelines (Department of Health 2004) ART patients in SA are required to make monthly visits to an ART program. It may be possible to reduce the frequency of these routine visits in patients who have received ART for some period of 
time and have responded well to treatment, thus decreasing the workload of ART program staff.

Of course, one of the crucial assumptions underlying our model is that ART, once started, has to be continued over a patient's lifetime. A cure for HIV would drastically reduce total health worker time spent per patient and eliminate the effect of feedback on HRHA need.

Policy implication 3: To achieve universal ART coverage, the inflow of HRHA into ART programs in developing countries will need to increase substantially. In SSA and SA, policies that increase this inflow will be much more effective if accompanied by interventions to decrease HRHA emigration rates.

We find that under a wide range of assumptions, the workforce required to treat HIVIAIDS patients will need to be increased dramatically if universal ART coverage is to be achieved. Such an increase may be especially difficult to achieve in SSA. In order to achieve universal ART coverage we estimate that 1,931 HRHA would need to be added annually to the HRHA workforce in SSA. According to the health worker-to-patient ratios measured by Hirschhorn and colleagues (2006), the 1,931 HRHA represent 1,931 to 3,862 doctors. To put this number into perspective, we can compare it with the existing medical school capacity in SSA: Eckert (2002) estimates that 5,100 students graduate each year from medical school in SSA. Allocating large proportions of those graduates to ART programs would very likely worsen the already severe shortage of doctors delivering non-ART health services in the region.

A number of options are available to increase the inflow of HRHA to developing countries. For one, health workers who currently work in the general health care system can leave their positions and become part of the workforce treating HIVIAIDS patients. In countries with generalized HIV epidemics, large proportions of inpatient and outpatient admissions are related to HIV (Bardgett, Dixon, and Beeching 2006; Dedicoat et al. 2003; Floyd et al. 1999). Since ART decreases health care utilization among HIV- 
positive people (Harling, Orrell, and Wood 2007), expansion of ART coverage may free up health care capacity to treat other patients. Thus in the short run, health systems in some developing countries may be able to sustain a shift of health workers into ART programs without detrimental effects on access to care that is not related to HIVIAIDS. However, these health systems are unlikely to be able to sustain large flows of health workers into ART programs over many years without an adverse impact on performance, especially if the integration of ART programs into the overall system is not well managed (Schneider et al. 2006).

Another option to increase the number of HRHA in developing countries is to attract international graduates to work in ART programs (Mullan 2007). SA, for instance, is actively recruiting international doctors and nurses to work in rural health centers (Rural Health Initiative 2007). However, the pool of physicians from developed countries who are willing to work in developing-country ART programs is probably quite limited, and international health workers may not be as effective as locally educated workers, for example, because of language difficulties or lack of familiarity with the local health care system.

We find that the increases in HRHA inflow required to achieve universal ART coverage are substantially reduced if HRHA emigration rates are decreased. A number of policy options exist to stem the current high levels of emigration from SSA to developed countries. These options include awarding "conditional scholarships" for health care education, whereby qualified candidates receive scholarships if they enter into a contract to deliver ART in SSA for a specific number of years following their graduation (Bärnighausen and Bloom 2009a; Bärnighausen and Bloom 2009b; Bärnighausen and Bloom 2009c); training health workers to deliver ART who are not internationally mobile, because their health care profession is not recognized in developed countries (such as health officers), but who can (partially) replace internationally mobile workers (such as doctors and nurses) (Dovlo 2004); and requiring developed countries to adopt so-called ethical recruiting practices, which limit the admission of health workers from developing countries (Stilwell et al. 2003). 
Health policy makers and researchers have called for an increased focus on HIV prevention and AIDS treatment among the health workforce (Shisana 2007). To evaluate the likely effectiveness of such measures, we examined the extent to which a reduction of HIV incidence among HRHA and an increase in HRHA ART coverage are effective interventions to increase the number of HRHA in the long run. We find that neither HIV prevention among health workers nor HRHA ART coverage are important determinants of long-term population ART coverage. However, these findings are certainly not arguments against ensuring that health workers have access to HIV prevention services and ART, which can be supported on a number of grounds (Macklin 2004). In addition, if the provision of effective HIV prevention and free ART in the workplace reduce health worker emigration, as Dovlo (2007) asserts they do, our results provide an indirect argument for such service provision.

For the predictions described in this manuscript, we used the number of people needing treatment and the number of people receiving treatment published by WHO in 2007 (WHO, UNAIDS, and UNICEF 2007). Recently, WHO has published updated numbers, reporting an increase in global ART coverage from 33\% to 42\% from 2008 to 2009 (WHO, UNAIDS, and UNICEF 2009). According to our predictions, such an increase would have required a substantial increase in the number of health workers delivering ART. While WHO does not provide estimates of the global number of HRHA in 2007 and 2008, it does report substantial increases of lower-skilled health workers in a number of individual countries and increased task-shifting from highly skilled to lowerskilled health workers (WHO, UNAIDS, and UNICEF 2009). In addition, it is possible that ART programs have increased the number of HRHA by providing high-paying jobs and opportunities for career progression and leadership, leading to reductions in health worker emigration rates.

Looking into the future, it is important to note that major international organizations and initiatives have realized that the size of the health workforce will need to be dramatically increased in the coming years if universal ART coverage is to be realized (WHO 2009, 
Global Fund to Fight AIDS, Tuberculosis and Malaria 2008). For instance, the United States President's Emergency Plan for AIDS Relief has committed itself to "support training of at least 140,000 new health care workers in HIVIAIDS prevention, treatment and care" by the end of 2013 (PEPFAR 2009). Although achieving universal ART coverage in the coming years is a daunting task, we can hope that through a combination of increased training of health workers, decreased health worker emigration, and changes in the delivery of ART the human resources to provide lifeprolonging treatment will be available to the millions of patients needing it. 


\section{References}

Badri, M., S. D. Lawn, and R. Wood. 2006. "Short-term risk of AIDS or death in people infected with HIV-1 before antiretroviral therapy in South Africa: a longitudinal study." Lancet 368 (9543): 1254-59.

Bardgett, H. P., M. Dixon, and N. J. Beeching. 2006. "Increase in hospital mortality from non-communicable disease and HIV-related conditions in Bulawayo, Zimbabwe, between 1992 and 2000." Tropical Doctor 36 (3): 129-31.

Bärnighausen, T. 2007. "Access to antiretroviral treatment in the developing world: a framework, review and health systems research agenda." Therapy 4(6): 753-66.

Bärnighausen, T., D. Bloom, S. Humair. 2007. "Human resources for treating HIVIAIDS: needs, capacities, and gaps." AIDS Patient Care and STDs 21 (11): 799-812.

Bärnighausen, T., and D. E. Bloom. 2009a. "'Conditional Scholarships' for HIVIAIDS health workers: educating and retaining the workforce to provide antiretroviral treatment in sub-Saharan Africa." Social Science and Medicine 68 (3): 544-51.

Bärnighausen, T., and D. E. Bloom. 2009b. "Financial incentives for return of service in underserved areas: a systematic review." BMC Health Services Research 9 (1): 86.

Bärnighausen, T., and D. E. Bloom. 2009c. "Designing financial-incentive programs for return of service in underserved areas: seven management functions." Human Resources for Health 7 (1): 52.

Blower, S., E. Bodine, J. Kahn, and W. McFarland. 2005. "The antiretroviral rollout and drug-resistant HIV in Africa: insights from empirical data and theoretical models." AIDS 19 (1): 1-14.

Bossert, T., T. Bärnighausen, D. Bowser, A. Mitchell, and G. Gedik. 2007. Assessing financing, education, management and policy context for strategic planning of human resources for health. Geneva: World Health Organization.

Braitstein, P., M. W. Brinkhof, F. Dabis, M. Schechter, A. Boulle, P. Miotti, R. Wood, C. Laurent, E. Sprinz, C. Seyler, D. R. Bangsberg, E. Balestre, J. A. Sterne, M. May, and M. Egger. 2006. "Mortality of HIV-1-infected patients in the first year of antiretroviral therapy: comparison between low-income and high-income countries." Lancet 367 (9513): 817-24.

Chen, L., and P. Hanvoravongchai. 2005. "HIVIAIDS and human resources." Bulletin of the World Health Organization 83 (4):243-44.

Clark, J. 2006. "HIV programmes in poor countries lack health workers." British Medical Journal 333 (7565): 412.

Clinton Foundation. 2007. "Clinton foundation HIVIAIDS initiative." http://www.clintonfoundation.org/cf-pgm-hs-ai-home.htm. Last accessed: September 1, 2007. 
Connelly, D., Y. Veriava, S. Roberts, J. Tsotetsi, A. Jordan, E. DeSilva, S. Rosen, and M. B. DeSilva. 2007. "Prevalence of HIV infection and median CD4 counts among health care workers in South Africa." South African Medical Journal 97 (2):115-20.

Dedicoat, M., K. Grimwade, R. Newton, and C. Gilks. 2003. "Changes in the patient population attending a primary health care clinic in rural South Africa between 1991 and 2001." South African Medical Journal 93 (10): 777-78.

Department of Health, South Africa (2004). National antiretroviral treatment guidelines. Pretoria: Department of Health.

Docquier, F., and A. Bhargava. 2007a. "A new panel data set on physician's emigration rates (1991-2004)." Report. Washington, D.C.: World Bank.

Docquier, F., and A. Bhargava. 2007b. "The medical brain drain: physicians' emigration rates 1991-2004." http://siteresources.worldbank.org/INTRES/Resources/DataSetDocquierBhargav a Medical BD100306.xls. Last accessed: June 20, 2009.

Dovlo, D. 2004. "Using mid-level cadres as substitutes for internationally mobile health professionals in Africa: a desk review." Human Resources for Health 2 (1): 7.

. 2007. "Migration of nurses from sub-Saharan Africa: a review of issues and challenges." Health Services Research 42 (3 Pt 2): 1373-88.

Eckhert, N. L. 2002. "The global pipeline: too narrow, too wide or just right?" Medical Education 36 (7): 606-13.

Floyd, K., R. A. Reid, D. Wilkinson, and C. F. Gilks. 1999. "Admission trends in a rural South African hospital during the early years of the HIV epidemic." Journal of the American Medical Association 282 (11): 1087-91.

Global Fund to Fight AIDS, Tuberculosis and Malaria. 2007. "Fighting AIDS." http://www.theglobalfund.org/en/. Last accessed: June 20, 2009.

Global Fund to Fight AIDS, Tuberculosis and Malaria. 2007. "Scaling up for impact: results report." http://www.theglobalfund.org/documents/publications/progressreports/ProgressR eport2008 en.pdf. Last accessed: October 6, 2009.

Hargreaves, J. R., and J. R. Glynn. 2002. "Educational attainment and HIV-1 infection in developing countries: a systematic review." Tropical Medicine \& International Health 7 (6): 489-98.

Harling, G., C. Orrell, and R. Wood. 2007. "Healthcare utilization of patients accessing an African national treatment program." BMC Health Services Research 7: 80.

Herbst, K., G. Cooke, T. Bärnighausen, A. Kany Kany, F. Tanser, and M.-L. Newell. 2009. "Adult mortality and antiretroviral treatment roll-out in a rural population in KwaZulu-Natal, South Africa." Bulletin of the World Health Organization 87: 754762. 
Hirschhorn, L. R., L. Oguda, A. Fullem, N. Dreesch, and P. Wilson. 2006. "Estimating health workforce needs for antiretroviral therapy in resource-limited settings." Human Resources for Health 4: 1.

Hogg, R. S., B. Yip, C. Kully, K. J. Craib, M. V. O'Shaughnessy, M. T. Schechter, and J. S. Montaner. 1999. "Improved survival among HIV-infected patients after initiation of triple-drug antiretroviral regimens." Canadian Medical Association Journal 160 (5): 659-65.

Hosseinipour, M., P. Kazembe, I. Sanne, and C. van der Horst. 2002. "Challenges in delivering antiretroviral treatment in resource poor countries." AIDS 16 (Suppl 4 (16): 177-87.

Institute of Medicine. 2007. PEPFAR implementation: progress and promise. Washington, DC: National Academies Press.

JLI (Joint Learning Initiative). 2004. Human resources for health - overcoming the crisis. Boston: Harvard University Press.

Kennedy, C., K. O'Reilly, A. Medley, and M. Sweat. 2007. "The impact of HIV treatment on risk behaviour in developing countries: a systematic review." AIDS Care 19 (6): 707-20.

Kingsley, B., and E. Juliet. 2001. "The World Bank and financing higher education in sub-Saharan Africa." Higher Education 42 (1): 1-34.

Kober, K., and W. Van Damme. 2004. "Scaling-up access to antiretroviral treatment in Southern Africa: who will do the job?" Lancet 364 (9428): 103-107.

Law, A. M., and W. D. Kelton. 2000. Simulation modeling and analysis. Boston: McGraw-Hill.

Macklin, R. 2004. Ethics and equity in access to HIV treatment: 3 by 5 initiative. Geneva: World Health.

Mannheimer, S. B., E. Morse, J. P. Matts, L. Andrews, C. Child, B. Schmetter, G. H. Friedland; Terry Beirn Community Programs for Clinical Research on AIDS. 2006. "Sustained benefit from a long-term antiretroviral adherence intervention: results of a large randomized clinical trial." Journal of Acquired Immune Deficiency Syndromes 43 (Suppl 1): S41-S47.

Marchal, B., V. De Brouwere, and G. Kegels. 2005. "Viewpoint: HIVIAIDS and the health workforce crisis: what are the next steps?" Tropical Medicine \& International Health 10 (4): 300-4.

Marchal, B., G. Kegels, and V. De Brouwere. 2004. "Human resources in scaling up HIVIAIDS programmes: just a killer assumption or in need of new paradigms?" AIDS 18 (15): 2103-5.

Médecins Sans Frontières. 2007a. "HIVIAIDS." http://www.doctorswithoutborders.org/news/hiv-aids/. Last accessed: December 5, 2007. 
. 2007b. Help wanted: confronting the health care worker crisis to expand access to HIVIAIDS treatment: MSF experience in Southern Africa. Johannesburg: Médecins Sans Frontières.

Merson, M. H., J. M. Dayton, and K. O'Reilly. 2000. "Effectiveness of HIV prevention interventions in developing countries." AIDS 14 (Suppl 2):S68-84.

Mullan, F. 2007. "Responding to the global HIVIAIDS crisis: a peace corps for health." JAMA 297 (7): 744-6.

Ncayiyana, D. J. 2004. "Doctors and nurses with HIV and AIDS in sub-Saharan Africa." British Medical Journal 329 (7466): 584-85.

Ooms, G., W. Van Damme, and M. Temmerman. 2007. "Medicines without doctors: why the Global Fund must fund salaries of health workers to expand AIDS treatment." PLoS Medicine 4 (4): e128.

Orrell, C., G. Harling, S. D. Lawn, R. Kaplan, M. McNally, L. G. Bekker, and R. Wood. 2007. "Conservation of first-line antiretroviral treatment regimen where therapeutic options are limited." Antiviral Therapy 12 (1): 83-88.

PEPFAR (President's Emergency Plan for AIDS Relief). 2007. "The United States president's emergency plan for AIDS relief." http://www.pepfar.govl. Last accessed: September 1, 2007.

. "Human capacity development". http://www.pepfar.gov/press/83015.htm. Last accessed: October 10, 2009.

Quinn, T. C., M. J. Wawer, N. Sewankambo, D. Serwadda, C. Li, F. Wabwire-Mangen, M. O. Meehan, T. Lutalo, and R. H. Gray. 2000. "Viral load and heterosexual transmission of Human Immunodeficiency Virus Type 1: Rakai project study group." New England Journal of Medicine 342 (13): 921-29.

Rehle, T., O. Shisana, V. Pillay, K. Zuma, A. Puren, and W. Parker. 2007. "National HIV incidence measures: new insights into the South African epidemic." South African Medical Journal 97 (3): 194-99.

Rural Health Initiative. 2007. "Welcome to rural health initiative South Africa." http://www.rhi.org.zal. Last accessed: June 25, 2007.

Schneider, H., D. Blaauw, L. Gilson, N. Chabikuli, and J. Goudge. 2006. "Health systems and access to antiretroviral drugs for HIV in Southern Africa: service delivery and human resources challenges." Reproductive Health Matters 14 (27): 12-23.

Shisana, O. 2007. "High HIVIAIDS prevalence among health workers requires urgent action." South African Medical Journal 97 (2):108-9.

Shisana, O., E. J. Hall, R. Maluleke, J. Chauveau, and C. Schwabe. 2004. "HIVIAIDS Prevalence among South African health workers." South African Medical Journal 94 (10): 846-50.

Shisana, O., T. Rehle, L. C. Simbayi, W. Parker, K. Zuma, A. Bhana, C. Connolly, S. Jooste, and V. Pillay. 2005. South African national HIV prevalence, HIV 
incidence, behaviour, and communication survey. Cape Town, South Africa: HSRC Press.

Stilwell, B., K. Diallo, P. Zurn, M. R. Dal Poz, O. Adams, and J. Buchan. 2003.

"Developing evidence-based ethical policies on the migration of health workers: conceptual and practical challenges." Human Resources for Health 1 (1): 8.

Tawfik, L., and S. Kinoti. 2003. The impact of HIVIAIDS on health systems and the health workforce in sub-Saharan Africa. Washington, DC: U.S. Agency for International Development, Bureau for Africa.

UNAIDS (Joint United Nations Programme on HIVIAIDS) and WHO (World Health Organization). 2007. AIDS epidemic update: special report on HIVIAIDS: December 2007. Geneva: UNAIDS.

UNAIDS. 2007. Estimated number of people newly infected with HIV globally, 19902007. http://data.unaids.org/pub/EPISlides/2007/071119 epislides en.pdf. Last accessed: October 6, 2009.

United Nations. 2007. "Political declaration on HIVIAIDS." http://data.unaids.org/pub/Report/2006/20060615_HLM_PoliticalDeclaration_AR ES60262_en.pdf. Last accessed: September 1, 2007.

Van Damme, W., K. Kober, and M. Laga. 2006. "The real challenges for scaling up ART in sub-Saharan Africa." AIDS 20 (5): 653-56.

WHO (World Health Organization). 2004. Scaling up antiretroviral therapy in resourcelimited settings: treatment guidelines for a public health approach. Geneva: WHO.

. 2006a. World Health Report 2006: working together for health. Geneva: WHO. . 2006b. "Antiretroviral therapy for HIV infection in adults and adolescents: recommendations for a public health approach. 2006 revision."

http://www.who.int/hiv/pub/guidelines/adult/en/index.html. Last accessed 29 October 2009. . 2007. "Global health atlas." http://www.who.int/globalatlas/default.asp. Last accessed: December 9, 2007).

WHO (World Health Organization), UNAIDS (Joint United Nations Programme on HIVIAIDS) and UNICEF (United Nations Children's Fund). 2007. Towards universal access. Geneva: WHO.

. 2009. Towards universal access: scaling up priority HIVIAIDS interventions in the health sector. Geneva: WHO.

Williams, B. G., E. L. Korenromp, E. Gouws, G. P. Schmid, B. Auvert, and C. Dye. 2006. "HIV infection, antiretroviral therapy, and CD4+ cell count distributions in African populations." Journal of Infectious Diseases 194 (10): 1450-58.

World Bank. 2007. World development indicators. Washington, DC: World Bank. 
Table 1: Parameter estimates for base cases

Base-case values

\begin{tabular}{|c|c|c|c|c|}
\hline Parameters & SSA & NSSA & SA & Sources \\
\hline HRHA work lifetime (years) & 17 & 30 & 18 & World Bank 2007 \\
\hline HRHA emigration rate (\%) & 0.09 & 0.02 & 0.28 & Docquier and Bhargava 2007b \\
\hline Initial HRHA HIV prevalence (\%) & 5.00 & 0.30 & 18.80 & UNAIDS/WHO 2007 \\
\hline HRHA HIV incidence rate (\%) & 0.421 & 0.024 & 2.400 & UNAIDS/WHO 2006, Rehle et al. 2007 \\
\hline Initial total number of HRHA & 1,340 & 675 & 325 & Hirschhorn et al. 2006 \\
\hline Number of people newly infected with HIV (per year) & $1,700,000$ & 734,000 & 571,000 & UNAIDS/WHO 2007 \\
\hline Initial size of total population needing ART & $4,800,000$ & $2,297,000$ & $1,000,000$ & WHO/UNAIDS/UNICEF 2007 \\
\hline Initial size of population needing but not receiving ART & $3,460,000$ & $1,622,000$ & 675,196 & WHO/UNAIDS/UNICEF 2007 \\
\hline Initial size of population receiving ART & $1,340,000$ & 675,000 & 324,804 & WHO/UNAIDS/UNICEF 2007 \\
\hline
\end{tabular}

HRHA = human resources to treat HIVIAIDS, ART = antiretroviral treatment, SSA = sub-Saharan Africa, NSSA = non-sub Saharan African low- and middle-income countries, $\mathrm{SA}=$ South Africa. HRHA emigration rate is the annual probability of death in HRHA. HRHA HIV incidence is the annual probability of HIV infection in HIV-negative HRHA. 
Table 2: Results of base-case scenarios and sensitivity analyses

\begin{tabular}{|c|c|c|c|c|c|c|c|c|c|c|}
\hline \multirow[b]{2}{*}{ Scenario } & \multirow[b]{2}{*}{ Year } & \multicolumn{3}{|c|}{ SSA } & \multicolumn{3}{|c|}{ NSSA } & \multicolumn{3}{|c|}{ SA } \\
\hline & & $\begin{array}{c}\text { ART } \\
\text { coverage } \\
(\%)\end{array}$ & $\begin{array}{c}\text { Number } \\
\text { of } \\
\text { Patients }\end{array}$ & $\begin{array}{c}\text { Number } \\
\text { of } \\
\text { HRHA }\end{array}$ & $\begin{array}{c}\text { ART } \\
\text { coverage } \\
(\%)\end{array}$ & $\begin{array}{c}\text { Number } \\
\text { of } \\
\text { Patients }\end{array}$ & $\begin{array}{c}\text { Number } \\
\text { of } \\
\text { HRHA }\end{array}$ & $\begin{array}{c}\text { ART } \\
\text { coverage } \\
(\%)\end{array}$ & $\begin{array}{c}\text { Number } \\
\text { of } \\
\text { Patients }\end{array}$ & $\begin{array}{c}\text { Number } \\
\text { of } \\
\text { HRHA }\end{array}$ \\
\hline \multirow[t]{3}{*}{ Base Case } & 0 & $28 \%$ & $4,800,000$ & 1,340 & $29 \%$ & $2,297,000$ & 675 & $33 \%$ & $1,000,000$ & 325 \\
\hline & 10 & $25 \%$ & $5,419,672$ & 1,332 & $28 \%$ & $2,427,224$ & 673 & $19 \%$ & $1,683,736$ & 321 \\
\hline & SS & $24 \%$ & $5,468,341$ & 1,334 & $28 \%$ & $2,437,104$ & 673 & $18 \%$ & $1,737,513$ & 321 \\
\hline \multirow[t]{2}{*}{ HRHA emigration rate $+25 \%$} & 10 & $22 \%$ & $5,328,464$ & 1,184 & $27 \%$ & $2,412,525$ & 647 & $16 \%$ & $1,645,635$ & 266 \\
\hline & SS & $22 \%$ & $5,334,304$ & 1,160 & $26 \%$ & $2,393,230$ & 616 & $16 \%$ & $1,693,854$ & 266 \\
\hline \multirow[t]{2}{*}{ HRHA emigration rate $-25 \%$} & 10 & $27 \%$ & $5,524,439$ & 1,506 & $29 \%$ & $2,442,686$ & 700 & $23 \%$ & $1,736,318$ & 402 \\
\hline & SS & $28 \%$ & $5,653,099$ & 1,569 & $30 \%$ & $2,490,373$ & 741 & $23 \%$ & $1,804,061$ & 406 \\
\hline \multirow[t]{2}{*}{ HRHA ART coverage $+25 \%$} & 10 & $25 \%$ & $5,419,899$ & 1,332 & $28 \%$ & $2,427,224$ & 673 & $19 \%$ & $1,683,278$ & 320 \\
\hline & SS & $24 \%$ & $5,466,596$ & 1,333 & $28 \%$ & $2,437,104$ & 673 & $18 \%$ & $1,737,512$ & 321 \\
\hline \multirow[t]{2}{*}{ HRHA ART coverage $-25 \%$} & 10 & $25 \%$ & $5,419,684$ & 1,332 & $28 \%$ & $2,427,224$ & 673 & $19 \%$ & $1,683,539$ & 320 \\
\hline & SS & $24 \%$ & $5,468,339$ & 1,334 & $28 \%$ & $2,437,104$ & 673 & $18 \%$ & $1,737,513$ & 321 \\
\hline \multirow[t]{2}{*}{ Number of new HRHA per year $+25 \%$} & 10 & $29 \%$ & $5,579,706$ & 1,595 & $30 \%$ & $2,467,646$ & 744 & $23 \%$ & $1,736,732$ & 400 \\
\hline & SS & $29 \%$ & $5,726,107$ & 1,662 & $33 \%$ & $2,568,433$ & 841 & $22 \%$ & $1,800,754$ & 402 \\
\hline \multirow[t]{2}{*}{ Number of new HRHA per year $-25 \%$} & 10 & $20 \%$ & $5,255,958$ & 1,063 & $25 \%$ & $2,387,178$ & 602 & $15 \%$ & $1,630,157$ & 241 \\
\hline & SS & $19 \%$ & $5,208,036$ & 999 & $22 \%$ & $2,306,445$ & 505 & $14 \%$ & $1,674,351$ & 241 \\
\hline \multirow[t]{2}{*}{ HRHA HIV incidence rate $+25 \%$} & 10 & $25 \%$ & $5,419,536$ & 1,332 & $28 \%$ & $2,427,881$ & 674 & $19 \%$ & $1,683,530$ & 321 \\
\hline & SS & $24 \%$ & $5,467,778$ & 1,333 & $28 \%$ & $2,437,152$ & 673 & $18 \%$ & $1,737,513$ & 321 \\
\hline \multirow[t]{2}{*}{ HRHA HIV incidence rate $-25 \%$} & 10 & $25 \%$ & $5,419,534$ & 1,332 & $28 \%$ & $2,427,195$ & 673 & $19 \%$ & $1,683,496$ & 321 \\
\hline & SS & $24 \%$ & $5,470,193$ & 1,335 & $28 \%$ & $2,437,102$ & 673 & $18 \%$ & $1,737,513$ & 321 \\
\hline \multirow[t]{2}{*}{ HRHA emigration rate $0 \%$} & 10 & $38 \%$ & $5,943,874$ & 2,254 & $32 \%$ & $2,492,097$ & 789 & $49 \%$ & $2,078,777$ & 1,017 \\
\hline & SS & $47 \%$ & $7,009,592$ & 3,303 & $39 \%$ & $2,750,795$ & 1,074 & $61 \%$ & $2,838,608$ & 1,728 \\
\hline \multirow[t]{2}{*}{ HRHA ART coverage $100 \%$} & 10 & $25 \%$ & $5,423,522$ & 1,338 & $28 \%$ & $2,427,844$ & 674 & $19 \%$ & $1,683,966$ & 321 \\
\hline & SS & $24 \%$ & $5,471,669$ & 1,337 & $28 \%$ & $2,438,069$ & 674 & $18 \%$ & $1,737,515$ & 321 \\
\hline HRHA emigration rate $0 \%$ and & 10 & $38 \%$ & $5,952,332$ & 2,270 & $32 \%$ & $2,492,754$ & 790 & $49 \%$ & $2,085,511$ & 1,030 \\
\hline HRHA ART coverage $100 \%$ & SS & $48 \%$ & $7,087,019$ & 3,402 & $39 \%$ & $2,753,451$ & 1,077 & $65 \%$ & $3,034,062$ & 1,978 \\
\hline
\end{tabular}

HRHA = human resources to treat HIVIAIDS, ART = antiretroviral treatment, SSA sub-Saharan Africa; NSSA non-sub Saharan African low- and middle-income countries, $\mathrm{SA}=$ South Africa, $\mathrm{SS}=$ steady state. HRHA emigration rate is the annual probability of death in HRHA. HRHA HIV incidence is the annual probability of HIV infection in HIV-negative HRHA. 
Table 3: Annual number of new HRHA needed to achieve universal ART coverage by year 10

\begin{tabular}{lrrr} 
& \multicolumn{3}{c}{ HRHA per year } \\
\cline { 2 - 4 } Scenario & SSA & NSSA & SA \\
\hline Base case & 1,931 & 532 & 1,085 \\
HRHA emigration rate 0\% & 1,262 & 470 & 399 \\
HRHA ART coverage 100\% & 1,931 & 532 & 1,085 \\
HRHA emigration rate 0\% and HRHA ART coverage 100\% & 1,262 & 470 & 399
\end{tabular}

$\mathrm{HRHA}=$ human resources to treat HIVAIDS, ART = antiretroviral treatment, SSA = sub-Saharan Africa, NSSA = non-sub Saharan African lowand middle-income countries, $\mathrm{SA}=$ South Africa. 
Figure 1: Population ART coverage under base-case assumptions

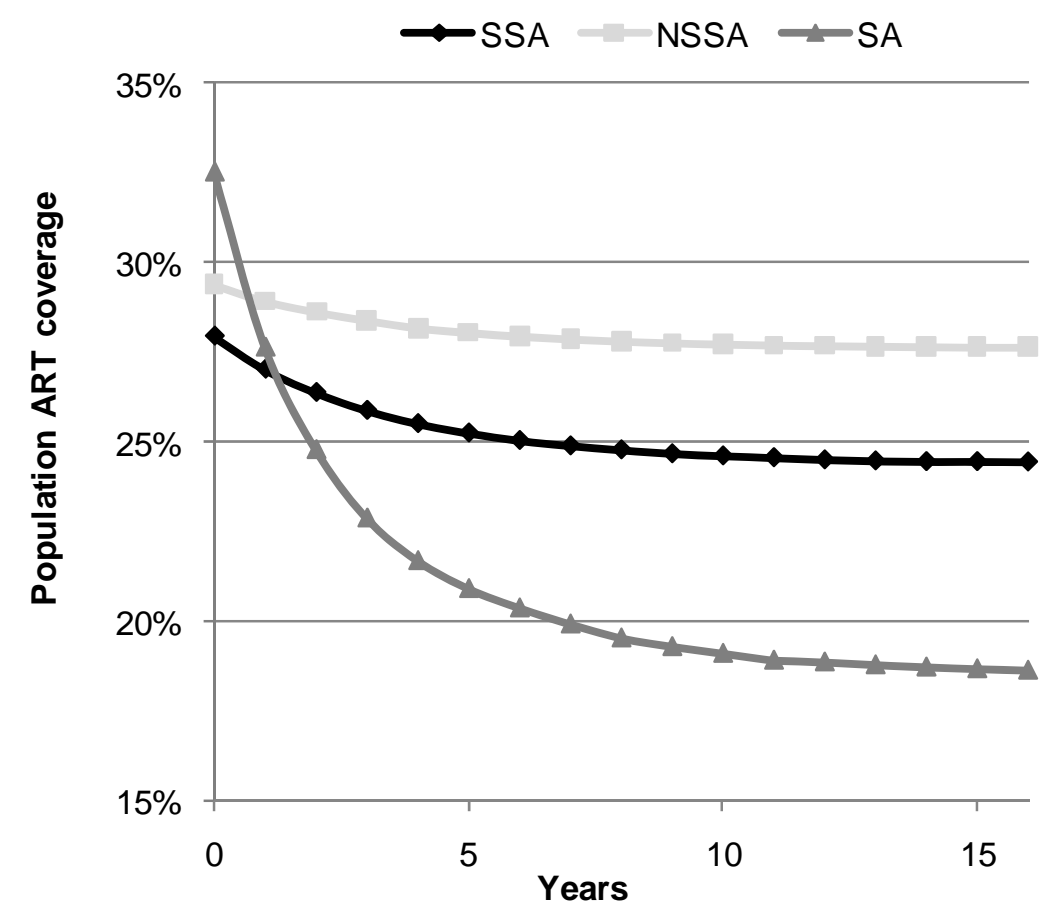

ART = antiretroviral treatment, SSA = sub-Saharan Africa, NSSA = non-sub Saharan African low- and middle-income countries, SA = South Africa 
Figure 2: Sustainability of universal ART coverage achieved by year 10 using a constant inflow rate of HRHA

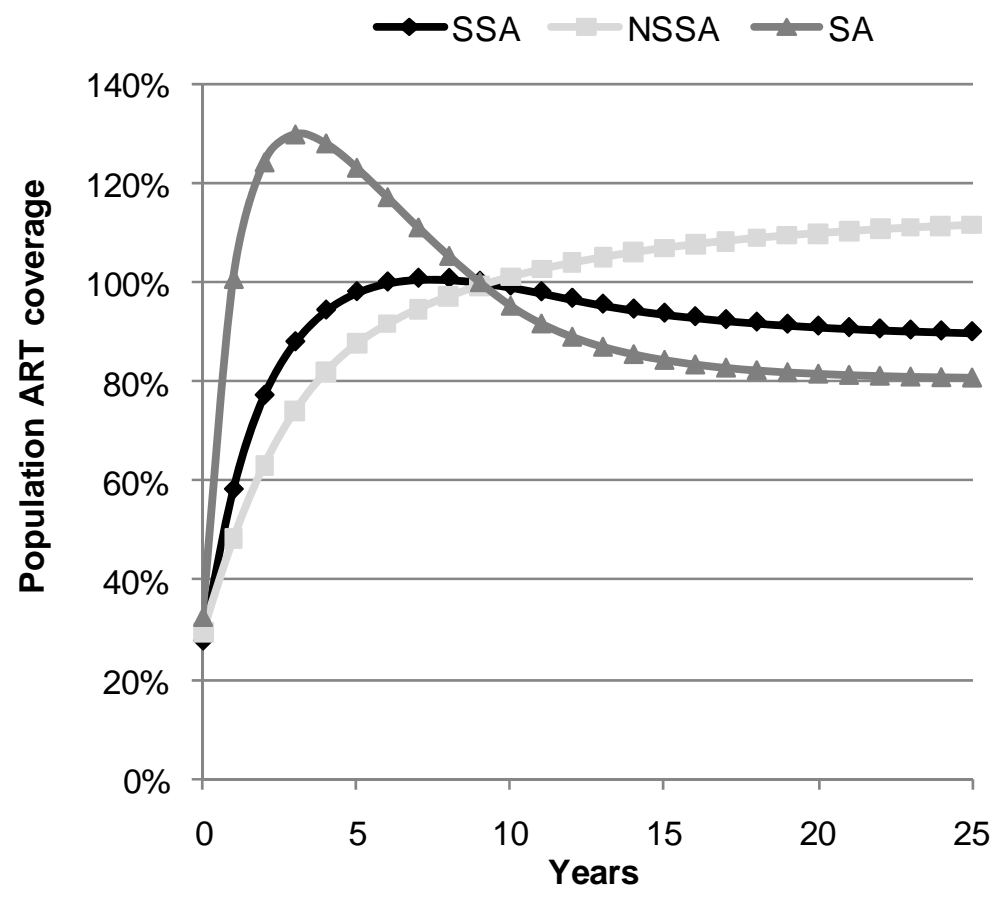

$\mathrm{HRHA}=$ human resources to treat HIVAIDS, ART = antiretroviral treatment, SSA = sub-Saharan Africa, NSSA = non-sub Saharan African lowand middle-income countries, SA = South Africa 


\section{Figure 3: Sensitivity of population ART coverage to model parameters}

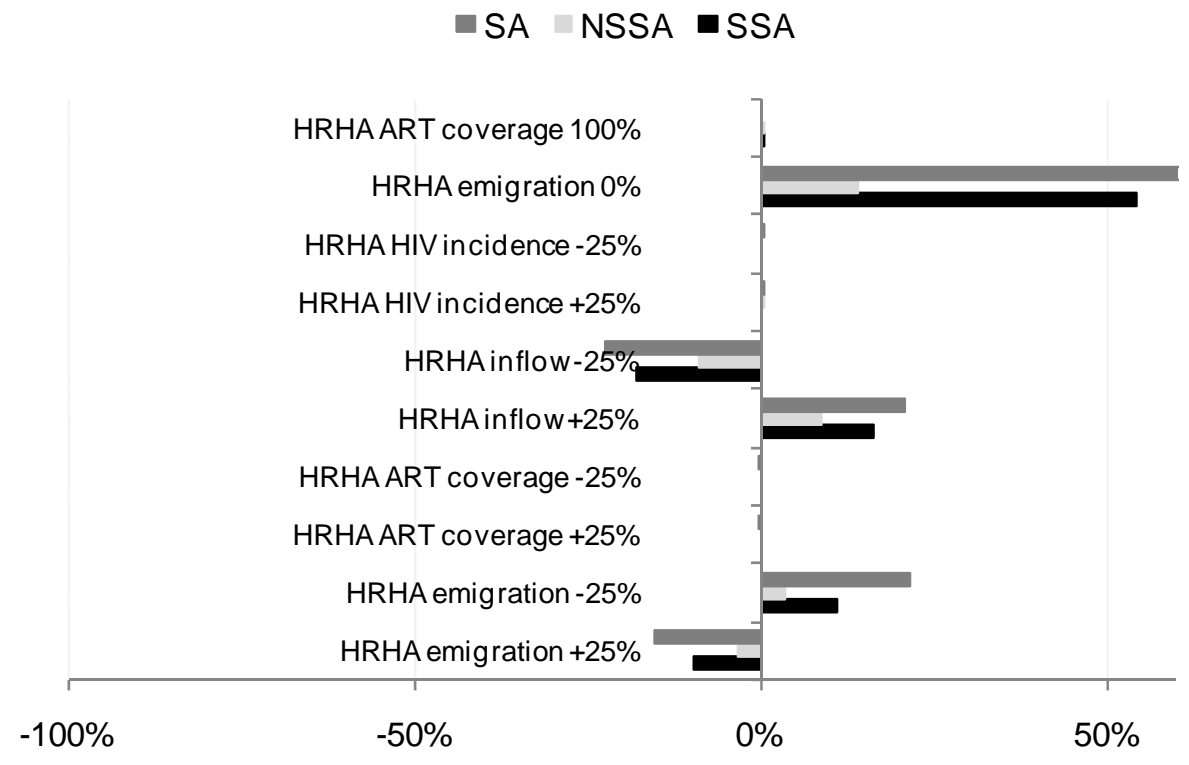

Percentage increase/decrease in ART coverage over basecase ART coverage by year 10

HRHA = human resources to treat HIVAIDS, ART = antiretroviral treatment, SSA = sub-Saharan Africa, NSSA = non-sub Saharan African lowand middle-income countries, SA = South Africa 
Figure 4: Steady-state HRHA required for SSA as a function of population coverage

$\rightarrow$ HRHA required with feedback - HRHA required without feedback

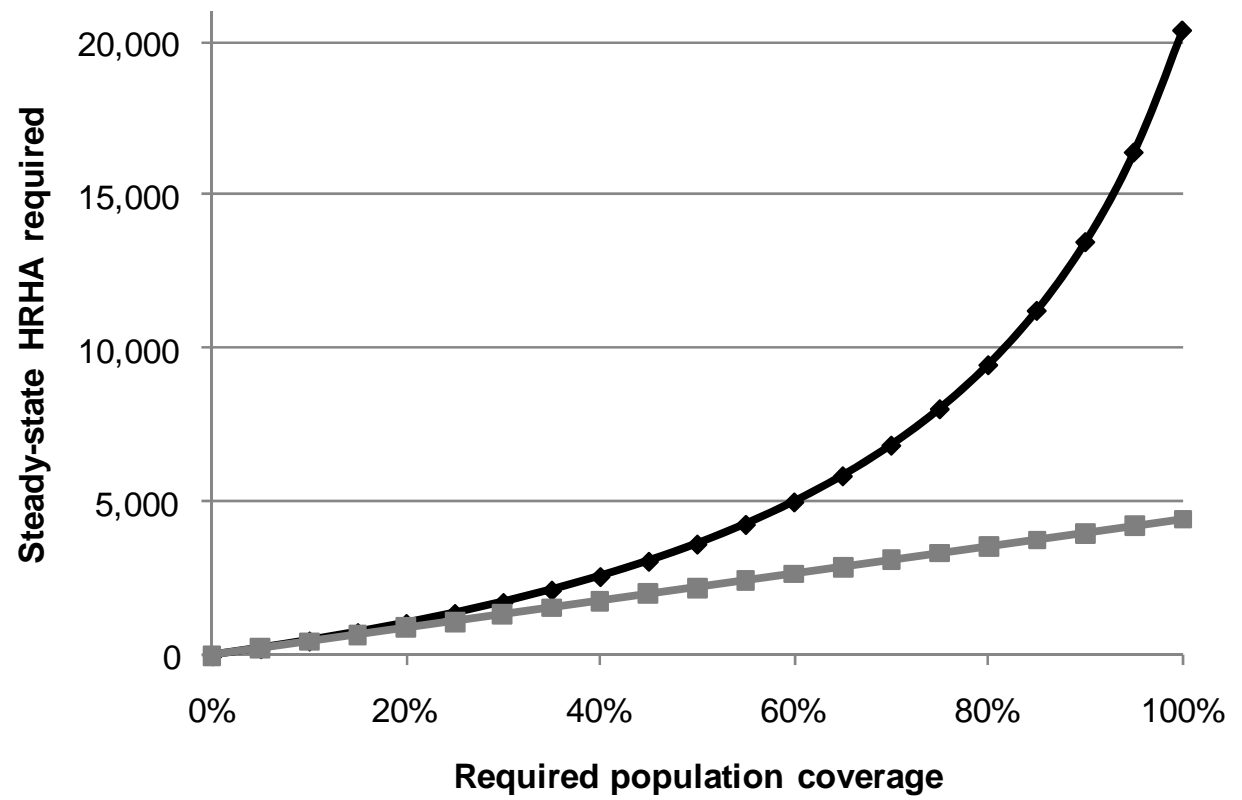

$\mathrm{HRHA}=$ human resources to treat HIVAIDS, SSA = sub-Saharan Africa 
Figure 5: Steady-state healthy and total HRHA pool size for SSA as a function of HRHA emigration rate

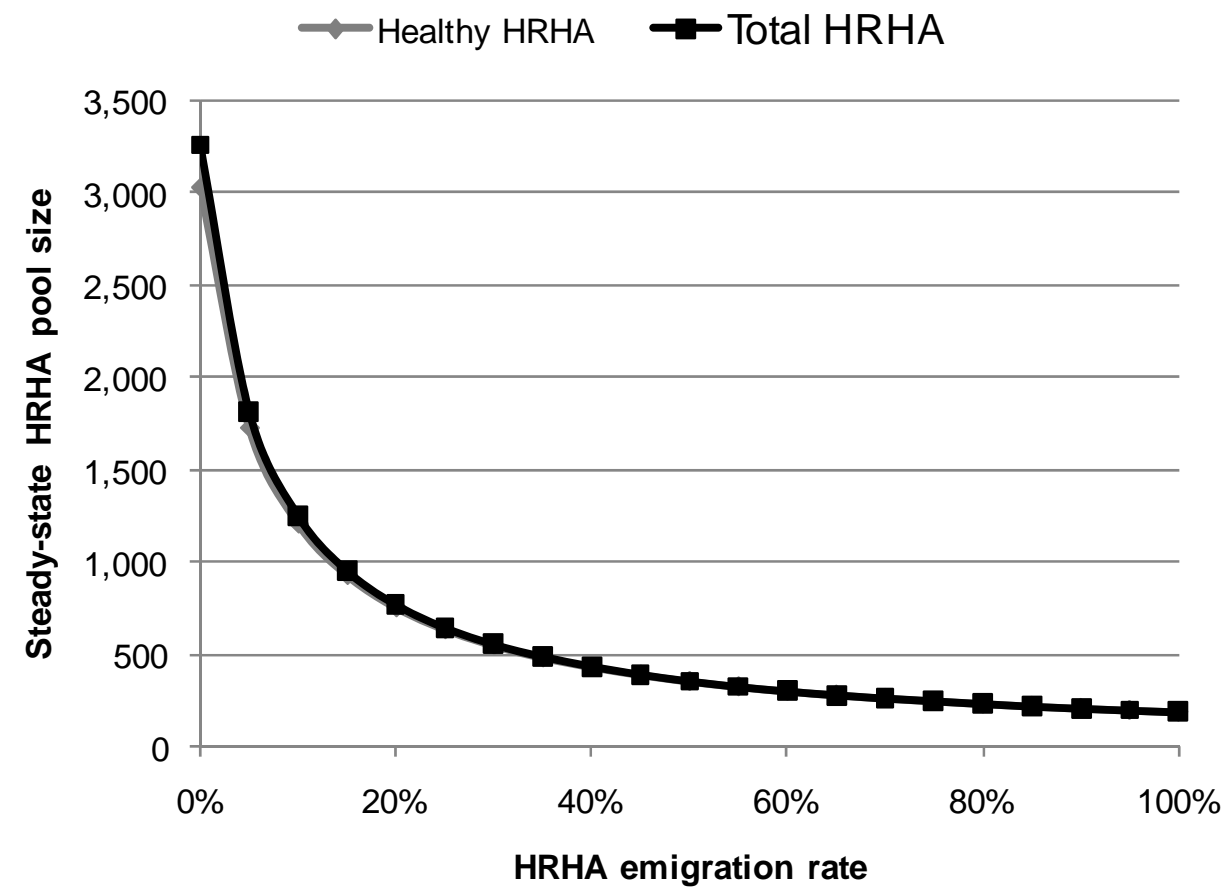

HRHA = human resources to treat HIVAIDS, SSA = sub-Saharan Africa 
Figure 6: Steady-state healthy and total HRHA pool size for SSA as a function of HRHA HIV incidence rate

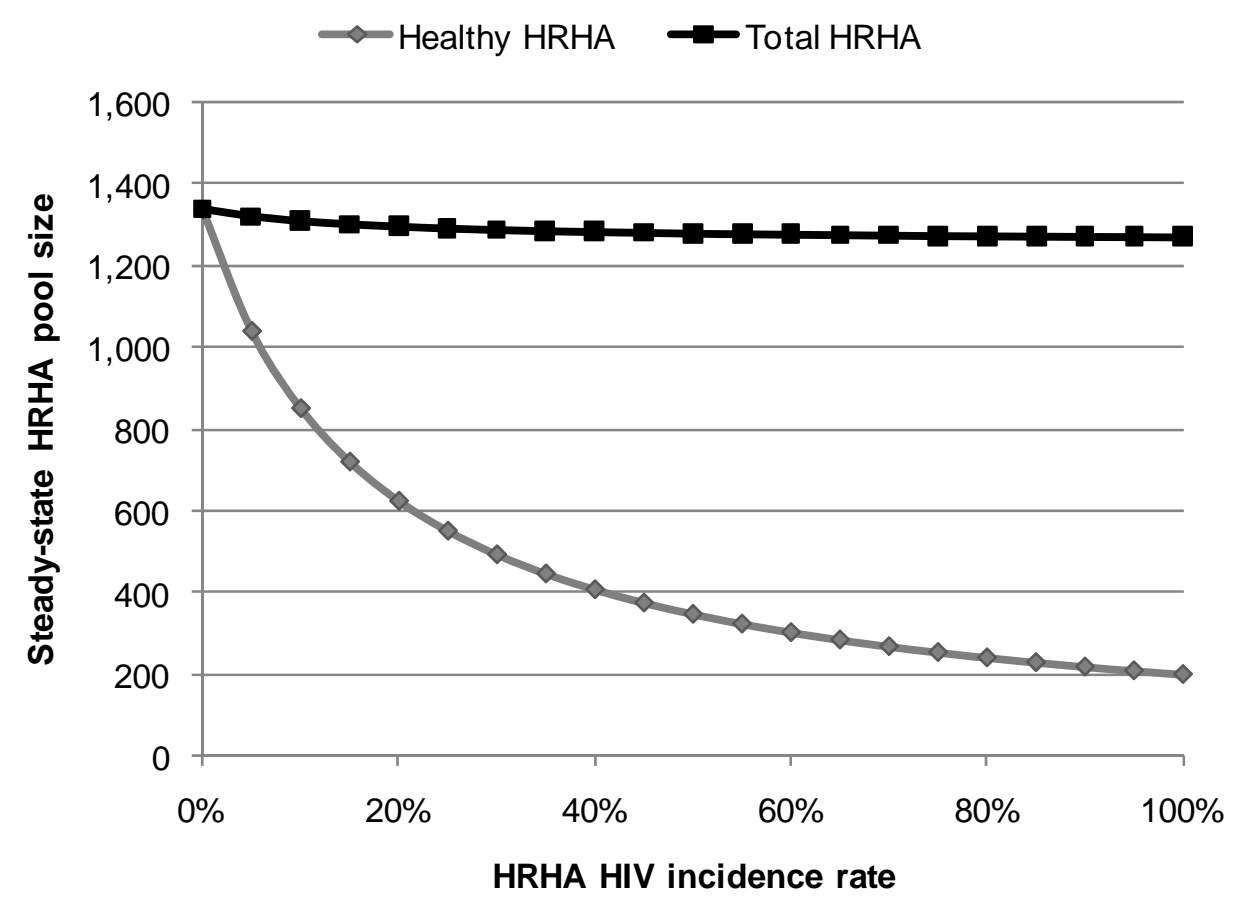

$\mathrm{HRHA}=$ human resources to treat HIVAIDS, SSA = sub-Saharan Africa 
Figure 7: Steady-state healthy and total HRHA pool size for SSA as a function of HRHA ART coverage

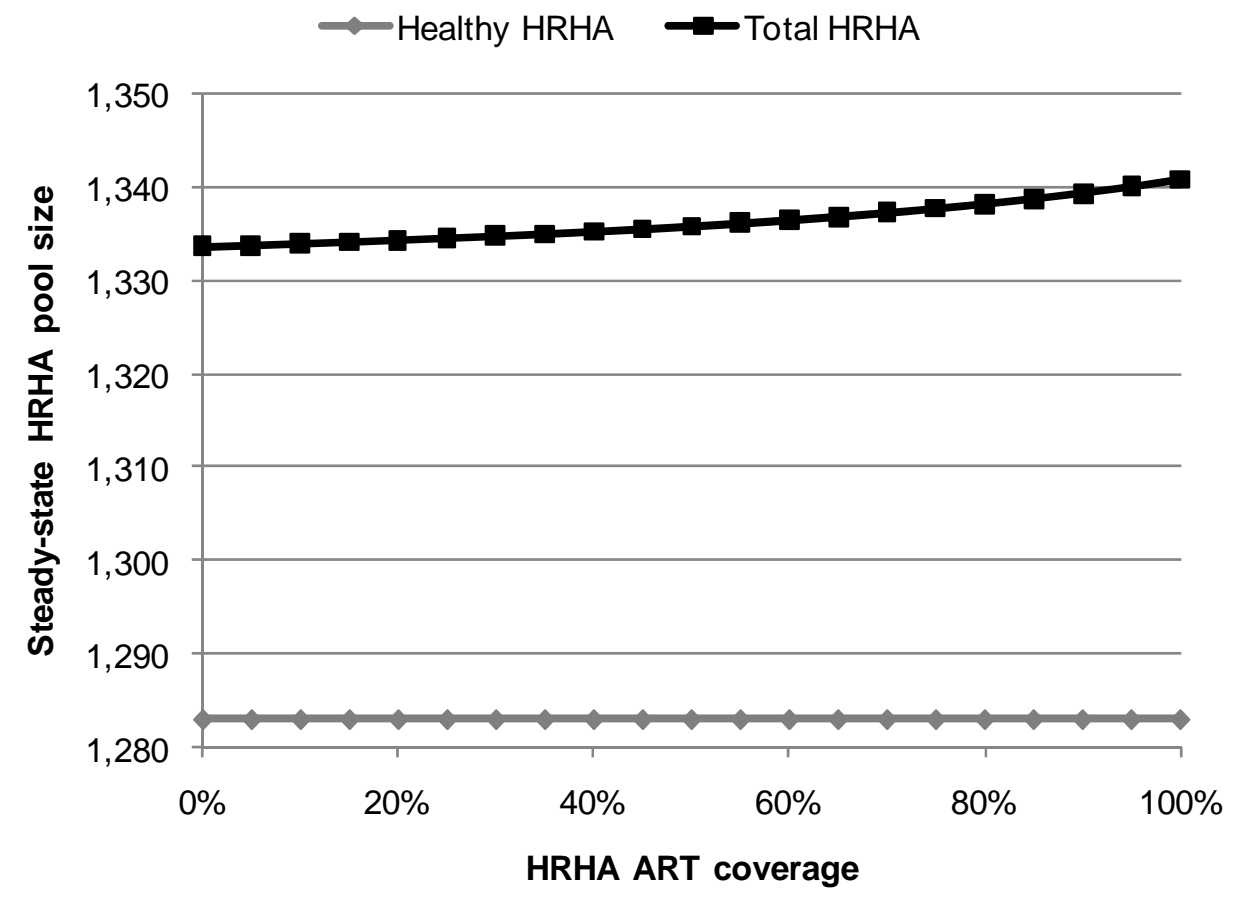

$\mathrm{HRHA}=$ human resources to treat HIVAIDS, ART = antiretroviral treatment, SSA = sub-Saharan Africa 
Figure 8: Steady-state population ART coverage for SSA as a function of HRHA emigration rate, HRHA HIV incidence rate, and HRHA ART coverage

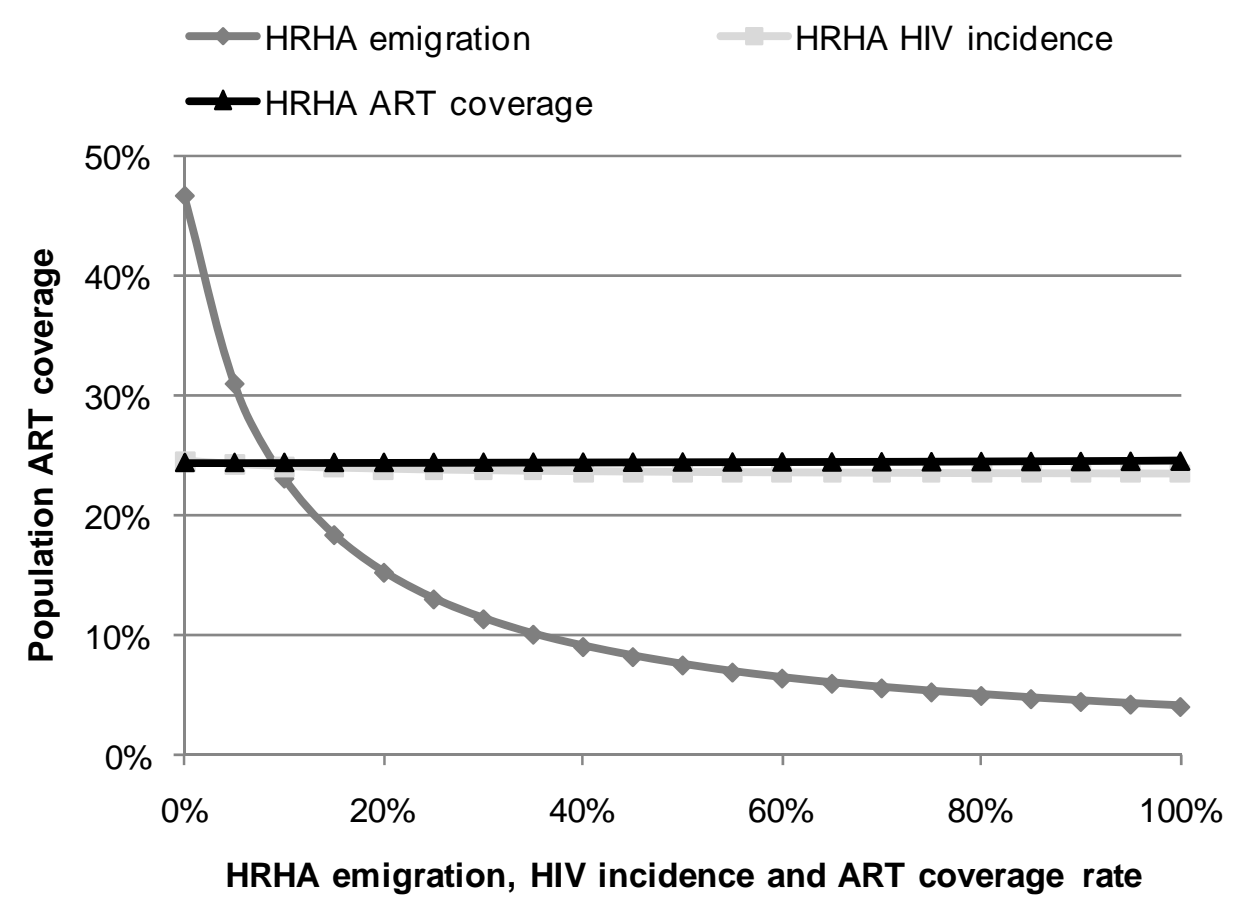

$\mathrm{HRHA}=$ human resources to treat HIVAIDS, ART = antiretroviral treatment, SSA = sub-Saharan Africa 